\title{
Padrões de precipitação e índices de erosividade para as chuvas de Seropédica e Nova Friburgo, RJ
}

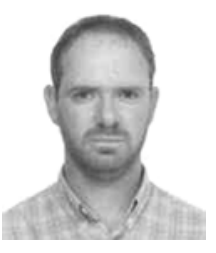

\author{
Daniel F. de Carvalho' ${ }^{1}$, Claudinei A. Montebeller ${ }^{2}$, Elenilson M. Franco ${ }^{3}$,
} Ricardo Valcarcel ${ }^{4}$, Ildegardes Bertol ${ }^{5}$

1 Departamento de Engenharia, UFRRJ. BR 465, km 7, CEP 23890-000, Seropédica, RJ. Fone: (21) $3787-3742$.
E-mail:carvalho@ufrj.br, Bolsista do CNPq (Foto)
${ }^{2}$ Doutorando na UFV. E-mail:cmontebeller@bol.com.br
${ }^{3}$ Estudante de Agronomia, Bolsista de Iniciação Científica PIBIC/UFRRJ/CNPq
${ }^{4}$ DCA/IF/UFRRJ, BR 465, km 7, CEP 23890-000, Seropédica, RJ. Fone: (21) 2682-1128. E-mail: ricval.rlk@terra.com.br
${ }^{5}$ Centro de Ciências Agroveterinárias, UDESC. CP 281, CEP 88520-000, Lages,SC. E-mail: a2ib@cav.udesc.br. Bolsista do CNPq

Protocolo $136-3 / 9 / 2003$ - Aprovado em 2/4/2004

Resumo: Desenvolveu-se este trabalho com o objetivo de determinar os diferentes padrões de chuvas erosivas naturais, calcular os índices de erosividade $\mathrm{El}_{30}$ e $\mathrm{KE}>25$ e ajustá-los aos dados mensais de precipitação para as regiões de Seropédica e Nova Friburgo, RJ. Com os resultados obtidos conclui-se que o padrão de chuva avançado é o de maior ocorrência para as duas regiões, correspondendo a 61 e $58 \%$ do número total das chuvas analisadas seguido, respectivamente, pelos padrões intermediário, com 24 e $24 \%$, e atrasado, com 15 e $18 \%$; os valores médios anuais de $\mathrm{El}_{30}$ foram de $5.472,5$ e de $5.431,2 \mathrm{MJ} \mathrm{mm} \mathrm{ha}^{-1} \mathrm{~h}^{-1}$, para Seropédica e Nova Friburgo, respectivamente, enquanto os valores médios anuais de KE $>25$ foram, respectivamente, de 76,8 e $83,5 \mathrm{MJ} \mathrm{ha}^{-1}$.

Palavras-chave: chuvas erosivas, $\mathrm{El}_{30}$, padrões de precipitação

\section{Rainfall patterns and erosion indices at Seropedica and Nova Friburgo, Rio de Janeiro - Brazil}

\begin{abstract}
This work was carried out in order to calculate the different storm patterns, the rainfall erosivity index $\left(\mathrm{El}_{30}\right.$ and $\left.\mathrm{KE}>25\right)$ and adjust them with the monthly precipitation data for Seropedica and Nova Friburgo, in the State of Rio de Janeiro, Brazil. Based on the results obtained, it was concluded that the advanced pattern is the most common in these regions, corresponding to $61 \%$ in Seropedica and $58 \%$ in Nova Friburgo, of the total number of analyzed storms. The percentages of intermediate and delayed patterns were, respectively, 24 and 15\%, for Seropedica and 24 and $18 \%$ for Nova Friburgo. The annual mean values of $\mathrm{El}_{30}$ were 5,472.5 and 5,431.2 $\mathrm{MJ} \mathrm{mm} \mathrm{ha-1} \mathrm{h}^{-1}$ for Seropedica and Nova Friburgo, respectively. For the KE $>25$ index, the annual mean values were 76.8 and $83.5 \mathrm{MJ} \mathrm{ha}^{-1}$ for Seropedica and Nova Friburgo, respectively.
\end{abstract}

Key words: erosive rainfall, $\mathrm{EI}_{30}$, rainfall patters

\section{INTRODUÇÃO}

O solo é um dos recursos naturais mais significativos para a humanidade, podendo ter sua capacidade produtiva comprometida pela degradação ocasionada pelo manejo inadequado e, conseqüentemente, pela erosão hídrica. Portanto, o conhecimento e a quantificação dos fatores que influenciam a erosão hídrica são fundamentais para o planejamento de uso e manejo do solo em bases conservacionistas em uma região.
O conhecimento e a quantificação das características físicas das chuvas associadas ao seu potencial erosivo, em dada região, são imprescindíveis na determinação de índices de erosividade adequados. No Brasil, poucos são os estudos básicos sobre características físicas das precipitações e também o são, geralmente, para um número reduzido de anos; além disso, os dados de perda de solo obtidos em experimentos de chuva natural e de longa duração, são escassos, o que tem dificultado o desenvolvimento de índices de erosividade adaptados para as condições brasileiras. 
O potencial da chuva em causar erosão pode ser avaliado por meio de índices de erosividade que se baseiam nas características físicas das chuvas de cada região. De acordo com Wischmeier \& Smith (1958), para regiões de clima temperado a melhor variável para avaliar a erosão é o produto da energia cinética (E) e sua intensidade máxima em $30 \mathrm{~min}$ $\left(\mathrm{I}_{30}\right)$, expressa como índice $\mathrm{EI}_{30}$, o qual vem sendo usado praticamente em todo o Brasil como parâmetro para avaliar a erodibilidade dos solos e a determinação das linhas isoerosivas.

A soma dos valores mensais de $\mathrm{EI}_{30}$, de um período de 22 anos, é o fator R da Equação Universal de Perdas de Solo EUPS, expresso em unidades de MJ mm ha ${ }^{-1} \mathrm{~h}^{-1}$. Com a EUPS pode-se estimar a perda média anual de solo, sendo a chuva o agente ativo no processo de erosão hídrica, pois provoca a desagregação das partículas do solo.

Lal (1976) afirma que o modelo de Wischmeier \& Smith (1958) subestima a energia cinética das chuvas nas regiões tropicais, pois ele não leva em conta a velocidade dos ventos, a distribuição de gotas de diferentes tamanhos nem as elevadas intensidades das chuvas. Assim, para as condições tropicais da África, Hudson (1965) encontrou melhor correlação das perdas de solo com o índice $\mathrm{KE}>25$, que considera a energia cinética total das chuvas com intensidade superior a $25 \mathrm{~mm} \mathrm{~h}^{-1}$. Por isso, Marques et al.(1998) argumentam que este índice poderia se correlacionar melhor com as perdas por erosão, em regiões tropicais. Apesar desta consideração, ambos os índices não contemplam as condições de umidade do solo antes da chuva nem o efeito erosivo do escoamento superficial.

Wagner \& Massambani (1988), ao analisarem precipitações predominantemente convectivas (pequeno volume, curta duração e alta intensidade), observaram que, na região de São Paulo, a equação para o cálculo de energia cinética obtida de acordo com os dados de precipitação, não diferiu da equação de Wischmeier \& Smith (1958), embora os índices de erosividade tenham sido determinados em relação a várias localidades do Brasil, como forma de estimar a capacidade das chuvas em provocar erosão.

As características da chuva que influenciam na sua erosividade, são volume total, duração e intensidade (Bertol,1993). Vários parâmetros podem ser utilizados para medir a erosividade da chuva; o problema central é escolher um que seja o mais adequado para a maioria dos casos, em especial porque cada ambiente e tempestade são únicos nas escalas temporal e espacial e, conseqüentemente, a erosão varia de diferentes maneiras.

A retirada da vegetação e a exposição do solo à ação direta das chuvas ou irrigação, causam perdas elevadas de solo e de água, além de alterações em suas propriedades físicas e químicas. De acordo com Lombardi Neto et al. (1988), a cobertura vegetal, principalmente o "mulch", absorve a energia cinética da chuva, não restando energia residual para provocar a desagregação do solo.

Além do potencial erosivo das precipitações, estudar o perfil dessas precipitações se torna elemento fundamental nos estudos de perda de solo, uma vez que as características das chuvas mudam de região para região (Flanagan et al.,1988). Assim, é de grande importância o agrupamento das chuvas com determinadas características em comum, para fins de comparação. Em dada região, o total de chuva anual poderá ser representado por um conjunto de chuvas de baixa intensidade e freqüentes e, em outra, de igual precipitação anual, duas ou três chuvas de alta intensidade podem representar até $80 \%$ da chuva ocorrida (Wischmeier,1962). No último caso, se as condições são semelhantes nos demais aspectos, a erosão terá efeitos bem mais drásticos.

Mehl (2000) padronizou as chuvas em três níveis diferentes, de acordo com o tempo de ocorrência do pico de intensidade em relação ao tempo total da chuva: i) padrão avançado, quando a maior intensidade ocorreu em um período de tempo menor que $30 \%$ a partir do tempo inicial da chuva em relação ao tempo total de duração; ii) padrão intermediário, quando a maior intensidade se deu entre 30 e $60 \%$ do tempo total da chuva, e iii) padrão atrasado, quando a maior intensidade ocorreu passados mais de $60 \%$ do tempo total de duração das chuvas. Os resultados obtidos pelo autor mostram que as maiores perdas de solo e água ocorrem nos padrões intermediário e atrasado, devido à maior umidade antecedente ao pico de maior intensidade da chuva. Em solos mais úmidos, a capacidade de infiltração é menor e a desagregação do solo pelo impacto das gotas da chuva também é favorecida, causando o selamento superficial e o escoamento de enxurrada.

O objetivo deste trabalho foi: determinar os diferentes padrões de chuvas erosivas naturais, calcular os índices de erosividade $\mathrm{EI}_{30}$ e $\mathrm{KE}>25$ e ajustá-los aos dados mensais de precipitação para as regiões de Seropédica e Nova Friburgo, RJ.

\section{MATERIAL E MÉTODOS}

O trabalho foi desenvolvido com dados de chuvas referentes ao período de 1974 a 1980 para Seropédica, RJ, e de 1974 a 1978 e 1980 para Nova Friburgo, RJ. Os pluviogramas diários foram fornecidos pelo Laboratório de Manejo de Bacias Hidrográficas do Instituto de Florestas (IF-UFRRJ), referentes às chuvas ocorridas nas estações experimentais sediadas nas localidades acima referidas, as quais estão cadastradas no INMET (Instituto Nacional de Meteorologia) como 83741 e 83745, respectivamente.

Apesar das séries históricas estudadas terem sido menores que 22 anos, período mínimo considerado adequado para ser utilizado na estimativa de perda média anual de solo por meio da EUPS, vale lembrar que, no Brasil, de modo geral são raras as séries históricas de pluviógrafos existentes com período superior a 10 anos (Pruski, 1996). Assim, diversos trabalhos sobre erosividade das chuvas têm sido feitos com séries inferiores às que foram utilizadas neste trabalho (Silva et al., 1997; Marques et al., 1998; Bertol et al., 2002). Conforme Wishmeier \& Smith (1958), uma chuva foi considerada independente quando estava separada de outra por no mínimo seis horas, com precipitação inferior a $1 \mathrm{~mm}$, sendo erosiva quando o volume total precipitado era superior a $10 \mathrm{~mm}$ ou quando era igual ou superior a $6 \mathrm{~mm}$ em um período máximo de $15 \mathrm{~min}$.

Para a determinação dos padrões de chuva, todas as chuvas individuais erosivas foram selecionadas, calculando-se a intensidade $\left(\mathrm{mm} \mathrm{h}^{-1}\right)$ e duração (h) de cada segmento do 
pluviograma com intensidade constate (Cabeda, 1976). A classificação das chuvas em padrões foi feita de acordo com Horner \& Jens (1941), tendo-se construído gráficos nos quais se relacionam as intensidades das chuvas e os tempos de duração. As chuvas foram então separadas em: a) padrão avançado (AV), quando a maior intensidade ocorreu no terço inicial do tempo total de duração da chuva; b) padrão intermediário (IN), quando a maior intensidade se verificou no terço intermediário; c) padrão atrasado (AT), quando a maior intensidade se deu no terço final do tempo total de duração da chuva.

Para a determinação dos índices de erosividade, cada chuva foi cotada manualmente em segmentos de intensidade uniforme. Para fins de comparação, a energia cinética por $\mathrm{mm}$ de chuva foi calculada, em cada segmento, pela metodologia de Wischmeier \& Smith (1958) utilizando-se a equação sugerida por Foster et al. (1981) que converte os dados para o Sistema Internacional de Unidades (Eq. 1), e pela metodologia proposta por Wagner \& Massambani (1988) que permite relacionar a energia cinética e a taxa de precipitação de chuvas predominantemente convectivas (Eq. 2).

$$
\begin{aligned}
& E=0,119+0,0873 \log I \\
& E=0,153+0,0645 \log I
\end{aligned}
$$

em que:

E - energia cinética por $\mathrm{mm}$ de chuva, $\mathrm{MJ} \mathrm{ha}^{-1} \mathrm{~mm}^{-1}$

I - intensidade de chuva, $\mathrm{mm} \mathrm{h}^{-1}$

As Eqs. 1 e 2 foram aplicadas em cada segmento com intensidade uniforme, para cada uma das chuvas. Os resultados obtidos nessas equações foram multiplicados pela lâmina de chuva precipitada em cada segmento e, em seguida, realizada a soma dos valores para um mesmo evento de chuva; assim, obteve-se a energia cinética total (Ec) para cada chuva.

A fim de se obter o índice $\mathrm{EI}_{30}$, em MJ mm ha ${ }^{-1} \mathrm{~h}^{-1}$, foi identificada a maior lâmina de chuva precipitada em $30 \mathrm{~min}$, com a qual se obteve a intensidade máxima de chuva observada nessa duração $\left(\mathrm{I}_{30}\right)$. Desta forma, foi calculado, para cada precipitação, o índice $\mathrm{EI}_{30}$.

$$
\mathrm{EI}_{30}=\mathrm{Ec} \mathrm{I}_{30}
$$

Para a obtenção do índice KE $>25$, utilizaram-se os mesmos parâmetros citados desconsiderando-se, porém, as precipitações com intensidades médias em cada segmento, inferiores a $25 \mathrm{~mm} \mathrm{~h}^{-1}$; desta forma, o índice KE $>25$ foi obtido por meio do somatório das energias cinéticas dos segmentos de chuva com intensidades maiores que $25 \mathrm{~mm} \mathrm{~h}^{-1}$.

Com os valores de $\mathrm{EI}_{30}$ e $\mathrm{KE}>25$, obtidos em cada precipitação, foi possível determinar os índices de erosividade mensais e, posteriormente, os anuais, para as duas localidades estudadas. Foi determinado, também, o coeficiente de chuva (Rc), conforme apresentado por Silva et al. (1997) e proposto por Lombardi Neto (1977), ou seja:

$$
\mathrm{Rc}=\mathrm{p}^{2} \mathrm{P}^{-1}
$$

em que:

$\mathrm{Rc}$ - coeficiente de chuva (mm)

$\mathrm{p}$ - precipitação média mensal (mm)

$\mathrm{P}$ - precipitação média anual $(\mathrm{mm})$

A curva de distribuição relativa acumulada da erosividade em função do tempo, foi obtida através dos valores médios mensais em relação ao valor médio anual, conforme Wischmeier \& Smith (1978), para os dois locais estudados.

\section{RESULTADOS E DISCUSSÃO}

A classificação das chuvas quanto à posição dos picos em relação ao tempo total mostrou que ambas as localidades apresentaram resultados semelhantes, o que pode ser visualizado na Tabela 1; estes, por outro lado, mostraram que o padrão avançado de chuva foi o de maior ocorrência, correspondendo a 61 e $58 \%$ do número total das chuvas, seguido pelos padrões intermediário, com 24 e $24 \%$ e, atrasado, com 15 e 18\%, para Seropédica e Nova Friburgo, respectivamente. Assim, na maioria dos casos os picos de maior intensidade ocorreram no início das chuvas.

\begin{tabular}{|c|c|c|c|c|c|c|c|c|}
\hline \multirow{2}{*}{ Ano } & \multicolumn{2}{|c|}{ Avançado } & \multicolumn{2}{|c|}{ Intermediário } & \multicolumn{2}{|c|}{ Atrasado } & \multicolumn{2}{|c|}{ Total } \\
\hline & $S$ & $\mathrm{NF}$ & $\mathrm{S}$ & $\mathrm{NF}$ & $\mathrm{S}$ & $\mathrm{NF}$ & $\mathrm{S}$ & $\mathrm{NF}$ \\
\hline 1974 & 17 & 7 & 4 & 9 & 4 & 6 & 25 & 22 \\
\hline 197 & 21 & 28 & 7 & s & & & 33 & 3 \\
\hline 1976 & 23 & 17 & 11 & 5 & 7 & & 41 & 29 \\
\hline 1977 & 15 & 13 & 9 & 12 & 5 & 3 & 29 & 28 \\
\hline 1978 & 13 & 15 & 7 & 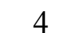 & 0 & 0 & 22 & 25 \\
\hline 1979 & 22 & & 5 & - & 7 & - & 34 & 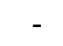 \\
\hline 1980 & 27 & 26 & 10 & 5 & 4 & 5 & 41 & 36 \\
\hline Tota & 138 & 10 & 53 & 42 & 34 & 3 & 225 & 182 \\
\hline$\%$ & 61,3 & 57,7 & 23,6 & 24,2 & 15,1 & 18,1 & 100 & 100 \\
\hline
\end{tabular}

Tabela 1. Número de chuvas classificadas para cada ano no período de 1974 - 1980, em Seropédica (S) e Nova Friburgo (NF), segundo diferentes padrões de precipitação

Para os padrões avançado, intermediário e atrasado, as intensidades médias dos picos das chuvas foram de 34; 28 e 21 $\mathrm{mm} \mathrm{h}^{-1}$ para Seropédica, respectivamente e, para Nova Friburgo, de 53; 42 e $59 \mathrm{~mm} \mathrm{~h}^{-1}$, respectivamente. Nas séries analisadas foi constatada apenas uma chuva intensa em Seropédica, com $109 \mathrm{~mm} \mathrm{~h}^{-1}$ e duração de mais ou menos $11 \mathrm{~min}$, enquanto em Nova Friburgo foram constatados 12 eventos de chuvas intensas, o mais intenso registrado no dia 11 de fevereiro de 1977, com $456 \mathrm{~mm} \mathrm{~h}^{-1}$ e duração de $1 \mathrm{~min}$.

Foi possível, desta forma, observar-se que chuvas de alta intensidade não foram freqüentes nessas regiões e, quando ocorreram, não se sustentaram por longo tempo, como se esperava, já que chuvas de alta intensidade têm curta duração (Hershfield, 1961). Portanto, em estudos de erosão hídrica do solo sob chuva simulada, chuvas de alta intensidade não devem se estender muito além do seu tempo médio de duração, sob pena de excederem as condições naturais e, então, 
superestimarem as perdas de solo e água. O tempo médio de duração das chuvas em Seropédica foi de 10 h e 29 min para o padrão avançado, de 6 h e 29 min para o intermediário e de 14 h para o padrão atrasado; já em Nova Friburgo esses valores foram, respectivamente, de $25 \mathrm{~h}$ e $45 \mathrm{~min}, 9 \mathrm{~h} \mathrm{e} 42 \mathrm{~min}$ e de $13 \mathrm{~h}$ e 53 min (Tabela 2).

Tabela 2. Número total de chuvas para cada padrão*, duração média e média dos picos para chuvas erosivas e intensas, em Seropédica e Nova Friburgo

\begin{tabular}{|c|c|c|c|c|c|}
\hline Características da chuva & & AV & IN & AT & Total \\
\hline \multicolumn{6}{|l|}{ A. Seropédica } \\
\hline \multirow[t]{2}{*}{ Chuva erosiva } & $\mathrm{N}$ & 138 & 53 & 34 & 225 \\
\hline & $\%$ & 61,3 & 23,6 & 15,1 & 100 \\
\hline Duração média & & 10h 17 & $6 \mathrm{~h} 29^{\prime}$ & $14 \mathrm{~h} \mathrm{00}$ & 49h 20' \\
\hline Média dos picos $\left(\mathrm{mm} \mathrm{h}^{-1}\right)$ & & 34,1 & 28,00 & 21,00 & 215,45 \\
\hline \multirow[t]{2}{*}{ Chuva intensa } & $\mathrm{N}$ & 1 & 0 & 0 & 1 \\
\hline & $\%$ & 100 & 0 & 0 & 100 \\
\hline Duração média & & $2 \mathrm{~h} 51$ ' & 0 & 0 & $2 \mathrm{~h} 51$ \\
\hline Média dos picos $\left(\mathrm{mm} \mathrm{h}^{-1}\right)$ & & 109,09 & 0 & 0 & 109,09 \\
\hline \multicolumn{6}{|l|}{ B. Nova Friburgo } \\
\hline \multirow[t]{2}{*}{ Chuva erosiva } & $\mathrm{N}$ & 105 & 44 & 33 & 182 \\
\hline & $\%$ & 57,7 & 24,2 & 18,1 & 100 \\
\hline Duração média & & $25 \mathrm{~h} 45^{\prime}$ & $9 \mathrm{~h} 42$ & $13 \mathrm{~h} 53^{\prime}$ & 49h 20' \\
\hline Média dos picos $\left(\mathrm{mm} \cdot \mathrm{h}^{-1}\right)$ & & 52,8 & 41,5 & 58,6 & 152,9 \\
\hline \multirow[t]{2}{*}{ Chuva intensa } & $\mathrm{N}$ & 9 & 0 & 3 & 12 \\
\hline & $\%$ & 75 & 0 & 25 & 100 \\
\hline Duração média & & $13 \mathrm{~h} 03^{\prime}$ & 0 & $5 \mathrm{~h} 10^{\prime}$ & $18 \mathrm{~h} \mathrm{13}$ \\
\hline Média dos picos $\left(\mathrm{mm} \cdot \mathrm{h}^{-1}\right)$ & & 176,6 & 0 & 241,0 & 417,6 \\
\hline
\end{tabular}

A Tabela 3 apresenta os valores mensais, anuais e médios de índice de erosividade, $\mathrm{EI}_{30}$, calculados pelas Eqs. 1 e 2, nas duas localidades estudadas. Comparando-se as duas metodologias para o cálculo do $\mathrm{EI}_{30}$, observa-se que não houve diferenças expressivas nos índices obtidos com a utilização dessas equações para Seropédica nem para Nova Friburgo. Analisando-se os coeficientes de variação, a máxima diferença entre as duas metodologias, para Seropédica, ocorreu no mês de novembro $(4,1 \%)$, seguido dos meses de outubro $(3,4 \%)$ e maio $(2,3 \%)$.

Em Nova Friburgo, (Tabela 3B), no entanto, a máxima diferença observada foi no mês de maio $(3,2 \%)$, seguida dos meses de novembro $(2,4 \%)$ e março $(2,1 \%)$. Diferenças dessas magnitudes foram também constatadas por Silva et al. (1997), estimando a erosividade das chuvas para a região de Goiânia; além disso, os maiores coeficientes de variação normalmente foram obtidos para os meses de menor ocorrência de precipitação, quando é menor o número de chuvas erosivas e, conseqüentemente, um número menor de valores do índice foi estudado.

Os valores médios anuais de $\mathrm{EI}_{30}$ foram de $5.472 \mathrm{MJ} \mathrm{mm} \mathrm{ha}^{-1} \mathrm{~h}^{-1}$ e de $5.43 \mathrm{MJ} \mathrm{mm} \mathrm{ha}^{-1} \mathrm{~h}^{-1}$, para Seropédica e Nova Friburgo, respectivamente. Com relação à série histórica estudada, os anos de 1977 e 1980 foram aqueles em que se observaram os maiores valores anuais de $\mathrm{EI}_{30}$, para as duas localidades. Os valores de $\mathrm{EI}_{30}$ foram semelhantes aos obtidos por Marques et al. (1998) na região de Sete Lagoas, MG (5.835 MJ mm ha ${ }^{-1} \mathrm{~h}^{-1}$ ) e por Bertol (1993) para Lages, SC (5.694 $\left.\mathrm{MJ} \mathrm{mm} \mathrm{ha}^{-1} \mathrm{~h}^{-1}\right)$ porém os valores de $\mathrm{EI}_{30}$ encontrados para Seropédica e Nova Friburgo são muito inferiores aos mostrados em outras regiões do País como, por exemplo, Goiânia, GO $\left(8.353 \mathrm{MJ} \mathrm{mm} \mathrm{ha}^{-1} \mathrm{~h}^{-1}\right.$ - Silva et al., 1997), Campos Novos, SC (6.329,3 MJ mm ha-1 $\mathrm{h}^{-1}$ - Bertol, 1994) e Manaus, AM (14.130 MJ mm ha ${ }^{-1} \mathrm{~h}^{-1}$ - Oliveira Júnior \& Medina, 1990) mas quando comparados com o $\mathrm{EI}_{30}$ estimado para o agreste pernambucano (3.551 MJ mm ha-1 $\mathrm{h}^{-1}$ - Campos Filho et al., 1992), os valores obtidos para Seropédica e Nova Friburgo foram muito superiores. Ressalta-se que o baixo valor do $\mathrm{EI}_{30}$ obtido para o agreste pernambucano não está relacionado com o índice pluviométrico mas com a intensidade de precipitação ocorrida.

O regime pluviométrico apresenta, nas regiões estudadas, período chuvoso entre outubro a março, coincidindo com as precipitações de verão, período onde também ocorrem chuvas convectivas freqüentes, fato que contribuiu para a similaridade dos resultados obtidos com os dois métodos de cálculo da energia cinética. Os resultados e as discussões apresentados seguem a metodologia proposta por Wischmeier \& Smith (1958), que é considerada padrão na obtenção do fator erosividade - $\mathrm{R}$ da EUPS. A Figura 1 mostra a variação média mensal do $\mathrm{EI}_{30}$ para as duas regiões estudadas. Como já verificado, os maiores valores de erosividade foram observados no verão, ocasionados por chuvas convectivas. Com exceção dos meses de outubro e novembro, o índice de erosividade estimado para a região da Baixada Fluminense (Seropédica) foi superior ao estimado para a região Serrana do Estado (Nova Friburgo). Para a região de Seropédica, a semeadura de culturas anuais a partir do mês de outubro possivelmente não acarretaria grandes prejuízos de erosão do solo, pela ação das chuvas erosivas, pois o relevo da região se caracteriza como suave ondulado. Mesmo nas encostas, a utilização da agricultura é quase que restrita ao cultivo da banana, sob forma extratitivista. Em Nova Friburgo, ao contrário, por se tratar de uma região serrana e se caracterizar como importante centro produtor de olerículas do Estado, o problema de erosão hídrica ocasionado por essas precipitações, provavelmente seria mais sério.

A Tabelas 4 (A e B) apresenta os resultados obtidos para o índice $\mathrm{KE}>25$. Os valores médios máximos do índice $\mathrm{KE}>25$, para Seropédica e Nova Friburgo foram, respectivamente, de 17,6 e de 21,1 $\mathrm{MJ} \mathrm{ha}^{-1}$, observados no mês de dezembro. Para as duas localidades, o índice médio anual foi de 76,8 e 83,5 $\mathrm{MJ} \mathrm{ha}^{-1}$, respectivamente. Comparando-se esses resultados com os obtidos por Marques et al. (1998), verificase que, apesar do $\mathrm{EI}_{30}$ apresentar valores nas duas localidades, o índice KE $>25$ indicou diferenças expressivas. Em Sete Lagoas,

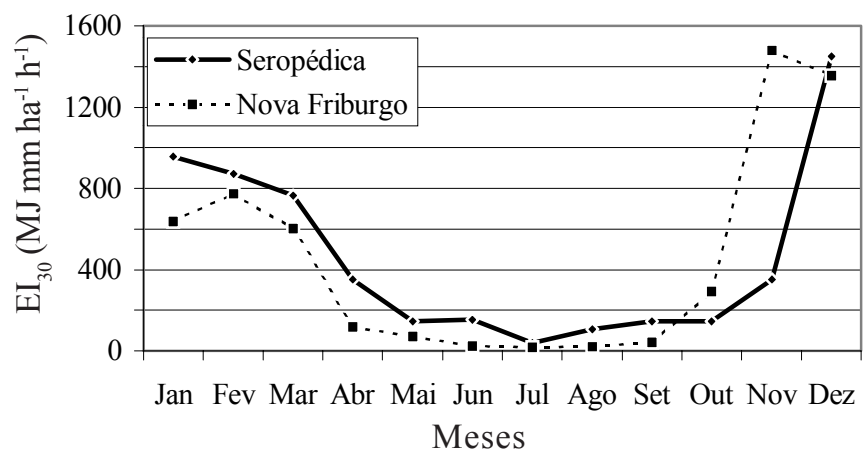

Figura 1. Variação mensal do índice $\mathrm{EI}_{30}$ para Seropédica e Nova Friburgo 
Tabela 3. Valores ( $\left.\mathrm{MJ} \mathrm{mm} \mathrm{ha}{ }^{-1} \mathrm{~h}^{-1}\right)$ mensais, anuais e médios dos índices de erosividade $\left(\mathrm{EI}_{30}\right)$ de Seropédica e Nova Friburgo , para o período de 1974 a 1980

\begin{tabular}{lllllllllll|l} 
Ano Jan. & Fev. & Mar. & Abr. & Mai. Jun. Jul. & Ago. & Set. & Out. & Nov. & Dez. & Total \\
\hline
\end{tabular}

A. Seropédica

\begin{tabular}{|c|c|c|c|c|c|c|c|c|c|c|c|c|c|}
\hline \multicolumn{14}{|c|}{$\mathrm{EI}_{30}$ (conforme Eq. 1) } \\
\hline 1974 & 387,0 & 0,0 & 666,0 & 506,4 & 158,6 & 40,5 & 0,0 & 0,0 & 298,3 & 202,1 & 250,5 & 2442,0 & 4951,3 \\
\hline 1975 & 758,7 & 1022,3 & 268,4 & 305,8 & 31,1 & 13,6 & 0,0 & 0,0 & 0,0 & 136,8 & 1100,4 & 531,3 & 4168,4 \\
\hline 1976 & 918,9 & 3259,3 & 313,0 & 206,1 & 643,5 & 606,9 & 42,6 & 53,7 & 65,1 & 444,1 & 65,3 & 1065,4 & 7684,0 \\
\hline 1977 & 1637,6 & 66,4 & 1818,9 & 503,6 & 24,8 & 361,9 & 84,0 & 132,7 & 249,0 & 0,0 & 103,0 & 4083,9 & 9065,8 \\
\hline 1978 & 324,8 & 347,6 & 391,5 & 553,3 & 0,0 & 0,0 & 0,0 & 0,0 & 26,0 & 96,2 & 123,0 & 666,2 & 2528,5 \\
\hline 1979 & 343,8 & 171,6 & 243,0 & 231,2 & 48,7 & 0,0 & 148,6 & 485,3 & 302,4 & 12,3 & 407,6 & 234,2 & 2628,9 \\
\hline 1980 & 2319,1 & 1233,2 & 1641,2 & 155,7 & 101,9 & 45,4 & 0,0 & 82,1 & 65,5 & 111,6 & 407,5 & 1117,4 & 7280,7 \\
\hline Média & 955,7 & 871,5 & 763,1 & 351,7 & 144,1 & 152,6 & 39,3 & 107,7 & 143,8 & 143,3 & 351,0 & 1448,6 & 5472,5 \\
\hline DP & 759,4 & 1156,7 & 677,1 & 165,3 & 226,7 & 238,1 & 57,9 & 174,0 & 133,5 & 149,9 & 359,0 & 1361,1 & 2575,5 \\
\hline $\mathrm{CV}$ & 79,5 & 132,7 & 88,7 & 47,0 & 157,3 & 156,0 & 147,3 & 161,5 & 92,9 & 104,6 & 102,3 & 94,0 & 47,1 \\
\hline \multicolumn{14}{|c|}{$\mathrm{EI}_{30}$ (conforme Eq. 2) } \\
\hline 1974 & 399,2 & 0,0 & 667,5 & 516,8 & 161,2 & 44,2 & 0,0 & 0,0 & 296,6 & 220,6 & 260,4 & 2541,6 & 5108,0 \\
\hline 1975 & 826,5 & 1044,4 & 286,1 & 310,4 & 34,3 & 15,5 & 0,0 & 0,0 & 0,0 & 142,0 & 1140,7 & 555,1 & 4355,0 \\
\hline 1976 & 933,2 & 3185,2 & 323,8 & 207,9 & 645,2 & 606,6 & 47,5 & 59,9 & 71,5 & 452,2 & 71,3 & 1090,6 & 7695,1 \\
\hline 1977 & 1654,9 & 66,6 & 1797,0 & 513,7 & 26,8 & 359,5 & 91,1 & 141,5 & 273,4 & 0,0 & 116,6 & 4047,1 & 9088,1 \\
\hline 1978 & 338,7 & 365,8 & 411,7 & 559,8 & 0,0 & 0,0 & 0,0 & 0,0 & 27,7 & 101,7 & 135,3 & 681,8 & 2622,6 \\
\hline 1979 & 357,7 & 195,8 & 255,9 & 237,0 & 49,2 & 0,0 & 159,6 & 501,2 & 327,3 & 14,1 & 426,8 & 252,0 & 2776,6 \\
\hline 1980 & 2317,6 & 1234,1 & 1645,4 & 170,5 & 111,9 & 49,5 & 0,0 & 88,9 & 71,7 & 126,4 & 511,5 & 1115,6 & 7443,3 \\
\hline Média & 975,4 & 870,3 & 769,6 & 359,5 & 147,0 & 153,6 & 42,6 & 113,1 & 152,6 & 151,0 & 380,4 & 1469,1 & 5584,1 \\
\hline DP & 753,4 & 1128,0 & 665,5 & 165,7 & 226,6 & 236,9 & 62,3 & 179,4 & 140,2 & 152,9 & 373,5 & 1354,1 & 2535,8 \\
\hline $\mathrm{CV}$ & 77,2 & 129,6 & 86,5 & 46,1 & 154,2 & 154,2 & 146,4 & 158,7 & 91,8 & 101,2 & 98,2 & 92,2 & 45,4 \\
\hline
\end{tabular}

B. Nova Friburgo

\begin{tabular}{|c|c|c|c|c|c|c|c|c|c|c|c|c|c|}
\hline \multicolumn{14}{|c|}{$\mathrm{EI}_{30}$ (conforme Eq. 1) } \\
\hline 1974 & 1348,5 & 122,3 & 183,9 & 0,0 & 0,0 & 120,6 & 0,0 & 0,0 & 0,0 & 648,1 & 293,9 & 989,5 & 3706,9 \\
\hline 1975 & 1272,8 & 2706,2 & 1263,2 & 48,6 & 52,9 & 18,2 & 27,4 & 0,0 & 0,0 & 173,4 & 296,1 & 880,0 & 6738,7 \\
\hline 1976 & 312,0 & 176,1 & 387,6 & 0,0 & 29,6 & 0,0 & 22,3 & 116,1 & 145,8 & 247,7 & 958,8 & 776,5 & 3172,5 \\
\hline 1977 & 76,4 & 0,0 & 780,0 & 33,1 & 254,7 & 0,0 & 62,9 & 0,0 & 94,2 & 271,8 & 1864,2 & 353,9 & 3891,2 \\
\hline 1978 & 515,3 & 177,4 & 256,6 & 217,0 & 53,7 & 0,0 & 0,0 & 0,0 & 0,0 & 358,7 & 3855,4 & 1820,8 & 7254,9 \\
\hline 1980 & 303,5 & 1451,7 & 734,9 & 9,6 & 42,1 & 0,0 & 0,0 & 0,0 & 11,7 & 52,1 & 1611,5 & 3305,8 & 7822,9 \\
\hline Média & 638,1 & 772,3 & 601,0 & 118,0 & 72,2 & 23 , & 18,8 & 19,3 & 42, & 292,0 & 1480,0 & 1354,4 & 5431,2 \\
\hline DP & 539,7 & 1089,0 & 406,6 & 126,0 & 91,6 & 48,3 & 24,8 & 47,4 & 62,8 & 202,6 & 1333,2 & 1069,4 & 2059,2 \\
\hline $\mathrm{CV}$ & 84,6 & 141,0 & 67,6 & 106,8 & 126,9 & 208,9 & 132,5 & 244,9 & 149,7 & 69,4 & 90,1 & 79,0 & 37,9 \\
\hline \multicolumn{14}{|c|}{$\mathrm{EI}_{30}$ (confor } \\
\hline 1974 & 1312,4 & 122,5 & 187,0 & 0,0 & 0,0 & 130,4 & 0,0 & 0,0 & 0,0 & 667,4 & 295,9 & 1026,5 & 3742,1 \\
\hline 1975 & 1327,8 & 2703,6 & 1258,2 & 53,4 & 57,6 & 20,1 & 28,7 & 0,0 & 0,0 & 183,5 & 319,1 & 883,0 & 6835,0 \\
\hline 1976 & 309,6 & 187,5 & 410,0 & 0,0 & 32,7 & 0,0 & 24,1 & 124,2 & 161,9 & 262,4 & 980,6 & 801,7 & 3294,6 \\
\hline 1977 & 84,9 & 0,0 & 775,2 & 134,6 & 262,6 & 0,0 & 65,3 & 0,0 & 101,6 & 285,7 & 1918,3 & 366,4 & 3994,5 \\
\hline 1978 & 543,2 & 194,7 & 279,0 & 223,9 & 56,5 & 0,0 & 0,0 & 0,0 & 0,0 & 365,7 & 3822,7 & 1805,7 & 7291,4 \\
\hline 1980 & 331,7 & 1454,2 & 729,1 & 307,7 & 45,9 & 0 , & 0,0 & 0,0 & 13,7 & 58,8 & 1706,4 & 3388,8 & 8036,3 \\
\hline Média & 651,6 & 777,1 & 606,4 & 119,9 & 75,9 & 25,1 & 19,7 & 20,7 & 46,2 & 303,9 & 1507,2 & 1378,7 & 5532,3 \\
\hline DP & 537,8 & 1085,3 & 397,5 & 126,1 & 93,9 & 52,2 & 25,9 & 50,7 & 69,2 & 206,2 & 1321,1 & 1090,9 & 2080,3 \\
\hline $\mathrm{CV}$ & 82,5 & 139,7 & 65,5 & 105,1 & 123,7 & 208,2 & 131,3 & 244,9 & 149,7 & 67,8 & 87,7 & 79,1 & 37,6 \\
\hline
\end{tabular}

MG, foi obtido um valor de 116,3 $\mathrm{MJ} \mathrm{ha}^{-1}$, mostrando a ocorrência, com mais freqüência, de precipitações com intensidades maiores que $25,0 \mathrm{~mm} \mathrm{~h}^{-1}$. Resultado semelhante foi obtido para a região de Goiânia, por Silva et al. (1997) que encontraram, para este índice, o valor de 129,8 $\mathrm{MJ} \mathrm{ha}^{-1}$.

Observando-se a Figura 2 (A e B) constata-se que os segmentos com maior inclinação das curvas de distribuição dos valores médios mensais acumulados para os índices $\mathrm{EI}_{30} \mathrm{e}$ $\mathrm{KE}>25$, representam os períodos com maior risco erosivo, os quais variam de uma localidade a outra. Em Seropédica, (Figura $2 \mathrm{~A}$ ), as chuvas apresentam, em média, maior capacidade erosiva de novembro a dezembro, seguindo-se o período de dezembro a março, enquanto em Nova Friburgo (Figura 2B) este período varia de outubro a dezembro. 
A.

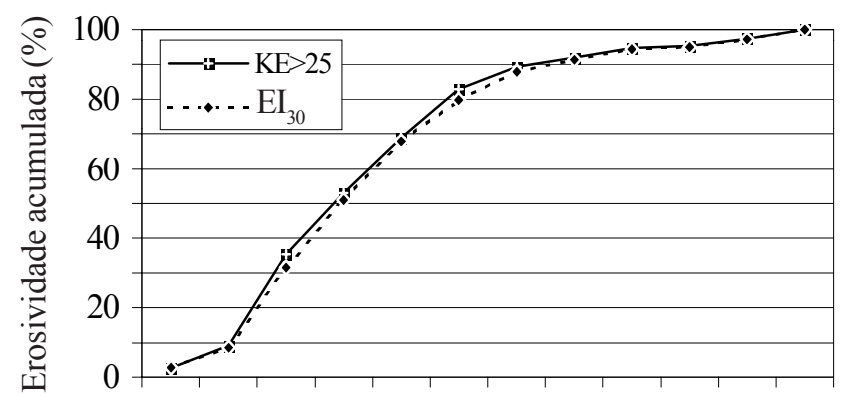

B.

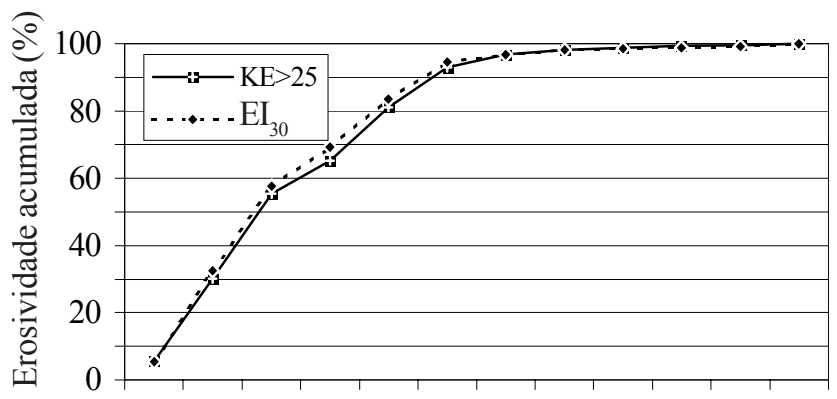

Out Nov Dez Jan Fev Mar Abr Mai Jun Jul Ago Set Meses

Figura 2. Curvas de distribuição da erosividade da chuva $\left(\mathrm{EI}_{30}\right.$ e KE>25) de Seropédica (A) e Nova Friburgo (B)

Em Seropédica, $80 \%$ do total de chuvas erosivas ocorreram do início do período chuvoso até o mês de março, quando os índices pluviométricos começaram a diminuir. Em Nova Friburgo, as erosividades foram mais concentradas, uma vez que $80 \%$ delas ocorreram no período de outubro a fevereiro. Observou-se, ainda, que o início do período chuvoso foi distinto nas duas localidades; em Seropédica, em outubro/ novembro a erosividade acumulada foi inferior a $10 \%$, enquanto em Nova Friburgo este valor esteve em torno de 25\%; além disso, em Seropédica o percentual acumulado do índice $\mathrm{EI}_{30}$ foi ligeiramente inferior ao $\mathrm{KE}>25$, durante o período chuvoso, enquanto em Nova Friburgo, se deu o inverso, fato este que indica, em geral, que as chuvas ocorridas em Seropédica apresentaram intensidades maiores que $25 \mathrm{~mm} \mathrm{~h}^{-1}$ devido, provavelmente, à maior proximidade da região com o oceano e, conseqüentemente, maior susceptibilidade à movimentação de massas de ar; no entanto, independentemente desta variação, os riscos de erosão em Nova Friburgo são superiores em função da existência de áreas com relevo mais movimentado.

Na Tabela 5 tem-se os valores da precipitação pluvial e do coeficiente de chuva, médios mensais e anual, para as duas localidades. Com os dados dessa tabela associados à distribuição percentual do índice $\mathrm{EI}_{30}$ para Seropédica e Nova Friburgo, confeccionou-se a Figura 3 (A e B), na qual se pode observar que a distribuição percentual da precipitação é muito semelhante para as duas localidades, embora existam expressivas diferenças no comportamento dos índices $\mathrm{EI}_{30} \mathrm{e}$ Rc. Para Seropédica, apesar de haver tendência única, a distribuição percentual do Rc foi semelhante apenas de junho a setembro, período com baixo índice pluviométrico, (Tabela 5), enquanto o oposto ocorreu em Nova Friburgo onde a semelhança nessa distribuição percentual foi mais evidente em todo o período, principalmente no início do período chuvoso e nos meses de março a setembro.

Esta variação regional é explicada pelo fato do índice $\mathrm{EI}_{30}$ estar diretamente relacionado com a intensidade da precipitação, enquanto o coeficiente $\mathrm{Rc}$ reflete apenas a relação entre os volumes totais médios mensais e anual (Bertol, 1993). Por isso, na região de Nova Friburgo os maiores volumes precipitados se correlacionaram melhor com as maiores intensidades de precipitação que no caso da região de Seropédica.

As informações anteriores são refletidas nas equações de regressão ajustadas ( 5 a 8 ) entre os dados de precipitação e

Tabela 4. Valores mensais $\left(\mathrm{MJ} \mathrm{ha}^{-1}\right)$, anuais e médios do índice de erosividade (KE>25) de Seropédica (A) e Nova Friburgo (B), para o período de 1974 a 1980

\begin{tabular}{|c|c|c|c|c|c|c|c|c|c|c|c|c|c|}
\hline Ano & Jan. & Fev. & Mar. & Abr. & Mai. & Jun. & Jul. & Ago. & Set. & Out. & Nov. & Dez. & Total \\
\hline \multicolumn{14}{|c|}{ A. Seropédica } \\
\hline 1974 & 8,2 & 0,0 & 8,9 & 6,0 & 5,3 & 1,5 & 0,0 & 0,0 & 8,3 & 3,5 & 5,0 & 20,9 & 67,5 \\
\hline 1975 & 6,8 & 23,4 & 2,9 & 5,9 & 0,0 & 0,0 & 0,0 & 0,0 & & 2,8 & 12,8 & 8,4 & 63,1 \\
\hline 1976 & 13,8 & 37,0 & 3,1 & 4,2 & 10,2 & 7,1 & 0,0 & 0,0 & 0,0 & 6,9 & 0,0 & 18,6 & 101,0 \\
\hline 1977 & 25,4 & 1,3 & 23,2 & 9,2 & 0,0 & 6,5 & 1,5 & 0,0 & 2,3 & 0,0 & 0,0 & 39,8 & 109,3 \\
\hline 1978 & 4,8 & 6,6 & 4,5 & 13,1 & 0,0 & 0,0 & 0,0 & 0,0 & 1,4 & 1,9 & 0,0 & 13,6 & 46,0 \\
\hline 1979 & 8,0 & 0,0 & 3,6 & 5,1 & 2,4 & 0,0 & 2,7 & 9,9 & 2,5 & 0,0 & 6,0 & 4,6 & 44,8 \\
\hline 1980 & 38,0 & 21,1 & 18,2 & 0,4 & 0,0 & 1,2 & 0,0 & 1,4 & 0,9 & 0,0 & 7,0 & 17,7 & 105,9 \\
\hline Média & 15,0 & 12,8 & 9,2 & 6,3 & 2,6 & 2,3 & 0,6 & 1,6 & 2,6 & 2,2 & 4,4 & 17,6 & 76,8 \\
\hline DP & 12,3 & 14,5 & 8,2 & 4,0 & 3,9 & 3,1 & 1,1 & 3,7 & 2,9 & 2,5 & 4,8 & 11,4 & 28,1 \\
\hline $\mathrm{CV}$ & 81,8 & 113,6 & 89,5 & 63,8 & 153,3 & 133,6 & 179,6 & 228,7 & 114,3 & 117,9 & 109,0 & 64,3 & 36,6 \\
\hline \multicolumn{14}{|l|}{ B. Nova $\mathrm{F}$} \\
\hline 1974 & 14,0 & 3,3 & 7,0 & 0,0 & 0,0 & 3,0 & 0,0 & 0,0 & 0,0 & 9,2 & 7,1 & 15,3 & 58,8 \\
\hline 1975 & 20,6 & 49,1 & 16,0 & 0,0 & 0,4 & 0,3 & 0,0 & 0,0 & 0,0 & 2,8 & 4,2 & 14,1 & 107,5 \\
\hline 1976 & 7,2 & 2,9 & 2,6 & 0,0 & 0,0 & 0,0 & 0,0 & 1,3 & 0,8 & 3,2 & 15,2 & 13,5 & 46,7 \\
\hline 1977 & 0,4 & 0,0 & 16,0 & 3,8 & 5,1 & 0,0 & 2,7 & 0,0 & 0,9 & 5,4 & 29,8 & 7,1 & 71,1 \\
\hline 1978 & 4,5 & 2,0 & 2,6 & 5,7 & 2,2 & 0,0 & 0,0 & 0,0 & 0,0 & 7,8 & 51,6 & 21,6 & 98,0 \\
\hline 1980 & 3,1 & 22,1 & 14,6 & 9,6 & 0,0 & 0,0 & 0,0 & 0,0 & 0,0 & 0,0 & 14,4 & 55,0 & 118,7 \\
\hline Média & 8,3 & 13,2 & 9,8 & 3,2 & 1,3 & 0,5 & 0,4 & 0,2 & 0,3 & 4,8 & 20,4 & 21,1 & 83,5 \\
\hline DP & 7,6 & 19,3 & 6,5 & 3,9 & 2,0 & 1,2 & 1,1 & 0,5 & 0,4 & 3,4 & 17,7 & 17,2 & 28,8 \\
\hline $\mathrm{CV}$ & 91,7 & 146,1 & 66,3 & 124,2 & 160,6 & 218,8 & 244,9 & 244,9 & 155,1 & 71,8 & 86,7 & 81,6 & 34,5 \\
\hline
\end{tabular}


Tabela 5. Valores médios mensais e anual da precipitação pluvial e coeficiente de chuva para Seropédica e Nova Friburgo, no período de 1974 a 1980

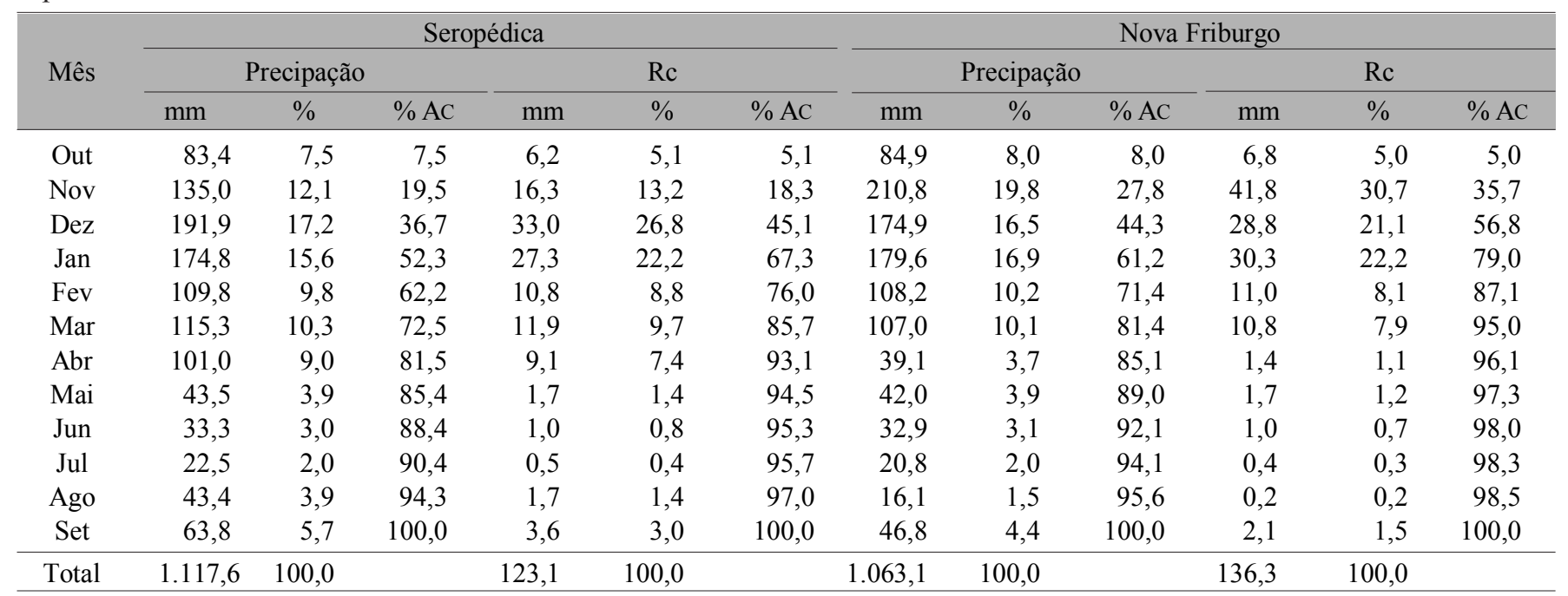

A.

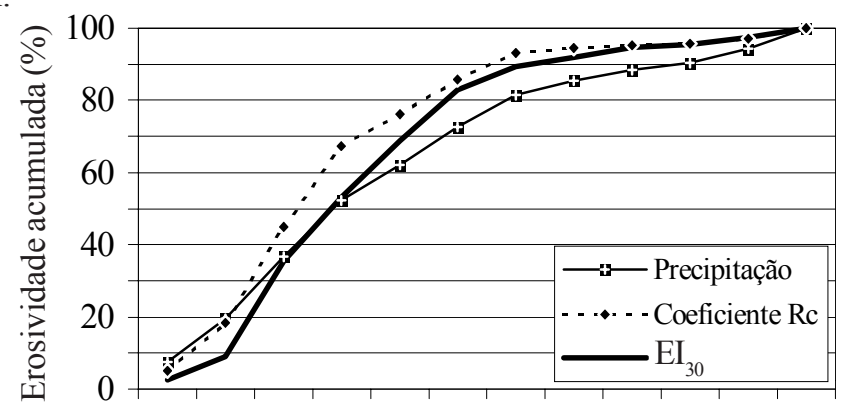

B.

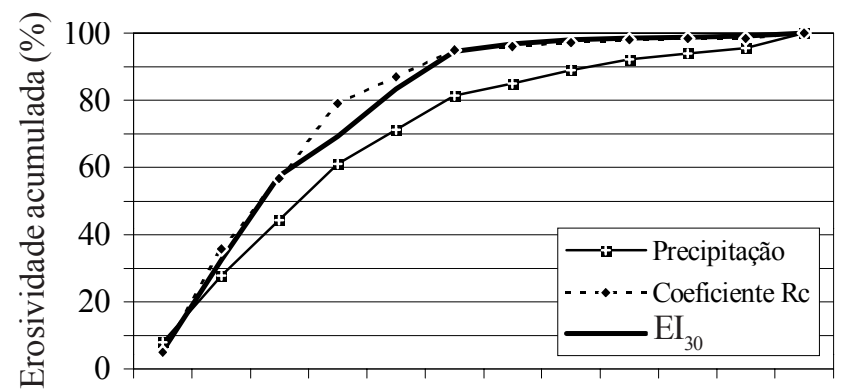

Out Nov Dez Jan Fev Mar Abr Mai Jun Jul Ago Set Meses

Figura 3. Curvas de distribuição da erosividade da chuva, precipitação pluvial e coeficiente de chuva para Seropédica (A) e Nova Friburgo (B)

coeficiente Rc com os dados de $\mathrm{EI}_{30}$. Para Seropédica, essas equações foram:

$$
\begin{aligned}
\mathrm{EI}_{30} & =7,171 \cdot \mathrm{P}+211,820 ; \mathrm{R}^{2}=0,78 \\
\mathrm{EI}_{30} & =38,138 \cdot \mathrm{Rc}+64,866 ; \mathrm{R}^{2}=0,82
\end{aligned}
$$

Em Nova Friburgo foram obtidas as equações:

$$
\begin{gathered}
\mathrm{EI}_{30}=7,216 \cdot \mathrm{P}+186,64 ; \mathrm{R}^{2}=0,87 \\
\mathrm{EI}_{30}=33,856 \cdot \mathrm{Rc}+67,991 ; \mathrm{R}^{2}=0,85
\end{gathered}
$$

Ao contrário dos ajustes obtidos por Bertol (1993) e Bertol (1994), para Lages (SC) e Campos Novos (SC), respectivamente, os coeficientes de correlação encontrados para Seropédica e Nova Friburgo indicaram que, para essas regiões, o índice mensal de erosividade pode ser estimado de modo satisfatório com base nos dados de precipitação e coeficiente de chuva Rc, os quais são de fácil obtenção.

\section{CONCLUSÕES}

1. O padrão avançado de chuva é o de maior ocorrência em Seropédica e Nova Friburgo, referentes a 61 e 58\% do número total de chuvas seguido, respectivamente, pelos padrões intermediário com 24 e 24\%, e atrasado, com 15 e $18 \%$.

2. Os valores médios anuais de $\mathrm{EI}_{30}$ foram de 5.472 e de $5.431 \mathrm{MJ} \mathrm{mm} \mathrm{ha}^{-1} \mathrm{~h}^{-1}$, para Seropédica e Nova Friburgo, respectivamente.

3. Para Seropédica e Nova Friburgo, os valores médios anuais de KE $>25$ foram, respectivamente, de 76,8 e de 83,5 $\mathrm{MJ} \mathrm{ha}^{-1}$.

4. Os coeficientes de correlação encontrados indicam que o índice mensal de erosividade pode ser estimado, de modo satisfatório, para Seropédica e Nova Friburgo, RJ, com base nos dados de precipitação pluvial, os quais são mais fáceis de serem obtidos.

\section{LITERATURA CITADA}

Bertol, I. Índice de Erosividade (EI30) para Lages (SC) - 1a Aproximação. Pesquisa Agropecuária Brasileira, Brasília, v. 28, n 4, p.515-521, 1993.

Bertol, I. Erosão hídrica em Cambissolo Húmico distrófico sob diferentes preparos do solo e rotação de cultura. Revista Brasileira de Ciência do Solo, Campinas, v.18, p.267-271, 1994.

Bertol, I; Schick, J.; Batistela, O.; Leite, D.; Visentin, D.; Cogo, N.P. Erosividade das chuvas e sua distribuição entre 1989 e 1998 no município de Lages(SC). Revista Brasileira de Ciência do Solo, Viçosa, v.26, p.455-464, 2002. 
Cabeda, M.S.V. Computation of storm El values. West Lafayette: Purdue University, 1976. 6 p.

Campos Filho, O.R.; Silva, I. de F.; Andrade, A.P. de; Leprun, J.C. Erosividade da chuva e erodibilidade do solo no agreste Pernambucano. Pesquisa Agropecuária Brasileira, v. 27, n 9, p.1363-1370, 1992.

Flanagan, D.C.; Foster, G.R.; Moldenhauer, W.C. Storm pattern effect on infiltration, runoff, and erosion. Transactions of the ASAE, St. Joseph, v. 31, n. 2, p. 414-420, 1988.

Foster, G.R.; McCool, D.K.; Renard, K.G.; Moldenhaeur, W.C. Conversion of the Universal Soil Loss Equation to SI units. Journal of Soil and Water Conservation, Batimore v.36 p. 335-359.1981.

Hershfield, D.N. Rainfall frequency atlas of the United States. U.S. Weather Bureau Tech. Paper 4,1961.

Horner, W.W.; Jens, S.W. Surface runoff determination from rainfall without using coefficients. Transactions of the ASAE, St. Joseph, v. 107, p, 1039-1117,1941.

Hudson, N.W. The influence of rainfall on the mechanics of soil erosion with to northern Rhodesia. Cape Town, University of Cape Town, 1965. Masters Dissertation

Lal, R. Soil erosion on alfisoils in Western Nigeria. III: Effects of rainfall characteristics. Geoderma, Amsterdam, v. p.16, 389-401. 1976.

Lombardi Neto, F.; Maria, I.C.; Castro, O.M.; Dechen, S.C.F; Vieira, S.R. Efeito da quantidade de resíduos culturais de milho nas perdas de solo e água. Revista Brasileira de Ciência do Solo, Campinas, v.12, n.1, p.71-75, 1988.

Lombardi Neto, F.; Rainfall erosivity - its distribution and relationship with soil loss at Campinas, Brazil. West Lafayette: Purdue University, 1977. 53p. Masters Dissertation
Marques, J.J.G.S.M.; Alvarenga, R.C.; Curi, N. Erosividade das chuvas de Sete Lagoas, MG. Pesquisa Agropecuária Brasileira, Brasília, v.33, n.5, p.285-288, 1998.

Mehl, H.U. Caracterização de padrões de chuvas em Santa Maria, RS, e sua relação com as perdas de solo e água entressulcos. Santa Maria: UFSM, 2000. 53p. Dissertação Mestrado

Oliveira Júnior, R.C.; Medina, B.F. A erosividade das chuvas em Manaus (AM). Revista Brasileira de Ciência do Solo, Campinas, v.14, n.2, p.235-239, 1990.

Pruski, F.F. Conservação de água e solos. Brasília, DF: ABEAS; Viçosa: UFV/DEA, 1996. 88p. Curso de Gestão de Recursos Hídricos para o Desenvolvimento Sustentados de Projetos Hidroagrícolas. Módulo, 7

Silva, M.L.N.; Freitas, P.L.; Blancaneaux, P.; Curi, N. Índices de erosividades das chuvas da região de Goiânia, GO. Pesquisa Agropecuária Brasileira, Brasília, v.32, n.10, p.275289. 1997.

Wagner, C.S.; Massambani, O. Análise da relação intensidade de chuva-energia cinética de Wischmeier \& Smith e sua aplicabilidade à região de São Paulo. Revista Brasileira de Ciência do Solo, Campinas, v.12, n.3, p.197-203, 1988.

Wischmeier, W.H. Storms and soil conservation. Journal of Soil and Water Conservation, Ankeny, v. 17, n. 2, p. 55-59,1962.

Wischmeier, W.H.; Smith, D.D. Rainfall energy and its relationship to soil loss. Transactions American Geophysical Union, Washington, v.39, p.285-291,1958.

Wischmeier, W.H.; Smith, D.D. Predicting rainfall erosion losses: a guide to conservation planning, Washington, DC: USDA, 1978. 58p. Agriculture Handbook, 537 